\title{
REMOVAL OF Pb(II) FROM INDUSTRIAL WASTEWATER BY USING VARIOUS NATURAL MATERIALS - A REVIEW
}

\author{
M.K. MONDAL \\ Department of Chemical Engineering and Technology, Institute of Technology, \\ Banaras Hindu University, Varanasi, Uttar Pradesh, India.
}

\begin{abstract}
Lead's history in science, medicine and technology has been overshadowed by its notoriety as a poison in homicides. Lead is viewed as being synonymous with toxicity. Dangerous lead concentration in natural, as well as industrial wastewater, is now a worldwide problem and often referred to as a 20th-21st century calamity. Existing overviews of lead removal include technologies that have traditionally been used (oxidation, precipitation/coagulation/membrane separation) with far less attention paid to adsorption. No previous review is available where readers can get an overview of the sorption capacities of both available and developed sorbents used for lead remediation. Most of the valuable available literature on lead remediation by adsorption has been incorporated. Lead sorption by commercially available carbons and other low-cost adsorbents developed from various natural materials are surveyed and critically reviewed and their sorption efficiency compared. Some commercially available adsorbents are also surveyed. An extensive table summarizes the maximum percentage of $\mathrm{Pb}$ (II) uptake, optimum $\mathrm{pH}$, isothermal model fit and thermodynamic parameters of various adsorbents. Some low cost adsorbents prepared from various natural materials are superior including bagasse fly ash, bone powder, sea nodule, olive cake, polymerized banana stem, tea waste, carbons developed from agricultural waste (coconut shell carbon and palm shell carbon), biosorbents (modified lignin and microspore), phosphogypsum and some commercial adsorbents, which included activated carbon, carbon aerogel tested for lead removal come out to be superior.
\end{abstract}

Keywords: adsorption, industrial wastewater effluent, lead removal, natural material, olive cake, sea nodule.

\section{INTRODUCTION}

Lead is a natural constituent of the earth's crust. It is present in a number of minerals, the principal ore being Galena (lead sulfide). Lead is present in air, water, food, soil, dust and snow as a contaminant [1]. Among the various organic and inorganic pollutants, heavy metals ions are very toxic and carcinogenic in nature. The presence of heavy metals in the aquatic environment has been of great concern because of their toxicity at lower concentration. Some metal ions are cumulative poisons capable of being assimilated and stored in the tissues of the organisms, causing noticeable adverse physiological effects. Lead is a metal ion which is very toxic and carcinogenic in nature. Inorganic forms of lead typically affect the central nervous system, peripheral nervous system, renal, gastro vascular, gastrointestinal and reproductive system [2]. Different industrial wastewater effluent, such as those from electroplating, mining, lead smelting and metal finishing, discharge significant amounts of lead ion in water bodies [3]. Lead is of particular interest because of its toxicity and widespread presence in the environment. The amount of lead in different industrial effluent and different organization standards are shown in the Tables 1 and 2. Various processes for removal of lead are greatly used like adsorption, ion exchange, reverse osmosis, precipitation and elctrodialysis, but adsorption is by far the most versatile and widely used method [4]. The other processes are usually not sufficient to reduce lead concentration to the level required by water quality standard [5]. Adsorption process has many advantages over other methods including recovery of metal value, selectivity, sludge free operation, cost effectiveness and meeting of strict discharge specification. A number of natural materials such as sea nodule, olive cake, bone powder, polymerized banana stem, and tea waste used as adsorbents have been reviewed for the removal of $\mathrm{Pb}(\mathrm{II})$. The sole aim 
Table 1: Industrial sources.

\begin{tabular}{lc}
\hline Name/type of industry & Amount of lead (mg/l) \\
\hline Electroplating & $0.663-25.39$ \\
Lead battery industry & $<0.03$ \\
Lead/Zinc mines & $0.2-0.3$ \\
Metal mines & $3-6$ \\
Coal combustion wastewater & 0.22 \\
Coal oven effluent & 0.03 \\
\hline
\end{tabular}

Table 2: Different standards given by different organizations.

\begin{tabular}{llc}
\hline Standard & \multicolumn{1}{c}{ Type } & Amount (mg/l) \\
\hline World Health Organization & Drinking water & 0.01 \\
U.S. Environmental Protection Agency & Wastewater & 0.05 \\
Bureau of Indian Standards & Wastewater & 0.1 \\
European Union & Drinking water & 0.01 \\
Wastewater, Industrial Discharge standards & Water body & 0.1 \\
& Navigation and irrigation purpose & 0.5 \\
Information Technology Research Lab. & Drinking water & 0.05 \\
United Nations Development Programme & Water body & $0.01-0.1$ \\
\hline
\end{tabular}

of the present work is to have an inexpensive adsorbent system for the removal of $\mathrm{Pb}$ (II) from industrial wastewater.

\section{ADSORPTION FUNDAMENTAL}

Adsorption is an effective method for removal of lead. It can be removed up to $95 \%$ by using suitable adsorbents. Various commercial adsorbents and biomaterials show good adsorption capacities. Adsorption is a process that occurs when a gas or liquid or solute (called adsorbate) accumulates on the surface of a solid or more rarely a liquid (adsorbent), forming a molecular or atomic film (adsorbate). The term "adsorption" was first coined in the late 19th century, but the process itself was not widely used until the 1940s and 1950s when activated carbon was first used for municipal water treatment. It is different from absorption, where a substance diffuses into a liquid or solid to form a "solution". The term sorption encompasses both processes, while desorption is the reverse process.

Adsorption is operative in most natural physical, biological, and chemical systems, and is widely used in industrial applications such as activated charcoal, synthetic resins and water purification. Adsorption, ion exchange and chromatography are sorption processes in which certain adsorptives are selectively transferred from the fluid phase to the surface of insoluble, rigid particles suspended in a vessel or packed in a column. Similar to surface tension, adsorption is a consequence of surface energy. In a bulk material, all the bonding requirements (be they ionic, covalent or metallic) of the constituent atoms of the material are filled. But, atoms on the (clean) surface experience a bond deficiency, because they are not wholly surrounded by other atoms. Thus, it is energetically favorable 
for them to bond with whatever happens to be available. The exact nature of the bonding depends on the details of the species involved, but the adsorbed material is generally classified as exhibiting physisorption or chemisorption.

There are a variety of standard methods to force an adsorbent to take-up then release certain components. One that applies only to gas-phase separations is cycling the pressure - resulting in what is called pressure swing adsorption (PSA). Another method, which works for either gases or liquids, is temperature swing adsorption.

\subsection{Uses of adsorption}

Adsorption is effective for purifications, e.g. taking a contaminant ranging from $1 \mathrm{ppb}$ to $1000 \mathrm{ppm}$ out of a stream of gas or liquid. In addition, adsorption is good for bulk separations, e.g. taking $1-50 \%$ out of a stream of gas, or may be $1-10 \%$ out of a liquid. Adsorption is also used for recovery of certain constituents (solvents from air), preventing pollution, purifying materials that will react, and so on. The above by no means represents a comprehensive list of the ways that adsorption can be used. As with any science, adsorption is constantly evolving and research is ongoing.

\subsection{Benefits of adsorption in industries}

Over the years, advancements in the field have resulted in substantial cost benefits from and expanded usage of adsorption in a number of industrial settings. One prominent example is in refineries and petrochemical plants where PSA has replaced cryogenic distillation as the most economical method for separating hydrogen from various compounds used in these settings. By replacing cryogenic distillation with PSA, refineries and petrochemical plants have been able to reduce costs by anywhere from $60 \%$ to $90 \%$. Another example of the cost benefits of adsorption is Adsorption Research, Inc.'s (ARI's), recent development of the Sulfur Dioxide Recovery System (SDRS). In this instance, the SDRS uses PSA techniques pioneered by ARI to enable foundry operators to recover and reuse more than $98 \%$ of the sulfur dioxide used in forming cold box molds for metal casting. According to ARI's estimates, a mid-size foundry running three shifts a day can expect to save up to $40 \%$ of their annual cost of $\mathrm{SO}_{2}$ by using the SDRS.

\subsection{Types of adsorption}

The adsorption is categorized on the basis of interactions involved between atoms, molecules of ions of adsorbate and adsorbent. According to the forces involved, two basic kinds of adsorption process can be distinguished.

\subsubsection{Physical adsorption}

It is a readily reversible phenomenon, is the result of intermolecular forces of attraction between molecules of solid and the substance adsorbed. Vander wall forces are responsible for this.

\subsubsection{Chemical adsorption}

Chemical adsorption is the result of chemical interaction between solid and adsorbed substance. The strength of chemical bond may vary considerably, and identifiable chemical compounds in the usual sense may not actually form, but adhesive force is generally much greater than that found in physical adsorption. The heat liberated during chemisorption is large, in order of the heat of chemical reaction The process is frequently irreversible, and on desorption the original substance will often be found 
to have undergone a chemical change. The same substance which, under conditions of low temperature, will undergo substantially only physical adsorption upon a solid will sometime exhibit chemisorption at higher temperatures, and both phenomena may occur at the same time.

\subsection{Adsorption isotherms}

Adsorption is usually described through isotherms, that is, functions which connect the amount of adsorbate on the adsorbent, with its pressure (if gas) or concentration (if liquid). Freundlich and Küster isotherm, the first isotherm, is a purely empirical formula valid for gaseous adsorbate:

$$
\frac{x}{m}=k P^{1 / n},
$$

where $x$ is the adsorbed quantity, $m$ is the mass of adsorbent, $P$ is the pressure of adsorbate and $k$ and $n$ are empirical constants for each adsorbent-adsorbate pair at each temperature. The function has an asymptotic maximum. As the temperature increases, the adsorbed quantity rises more slowly and more pressure is required to achieve the maximum.

\subsubsection{Langmuir adsorption isotherm}

Langmuir developed an adsorption model, which is valid for a single layer adsorption. The assumptions underlying are:

1. The molecules are adsorbed on the definite sites on the surface of the adsorbent.

2. Each site can accommodate only one molecule (monolayer). The area of site is fixed and its magnitude is determined solely by the geometry of the surface.

3. The adsorption energy is the same at all the sites.

4. The adsorbed molecules cannot migrate across the surface or interact with the neighboring molecules.

There are always imperfections on the surface, adsorbed molecules are not necessarily inert, the mechanism is clearly not the same for the very first molecules as for the last to adsorb. The fourth condition is the most troublesome, as often more molecules can adsorb on the monolayer, but this problem is solved by the Braunauer-Emmet-Teller (BET) isotherm. Langmuir suggests that adsorption takes place through this mechanism:

$$
\mathrm{A}_{(\mathrm{g})}+\mathrm{S} \rightleftharpoons \mathrm{AS},
$$

where $\mathrm{A}$ is a gas molecule and $\mathrm{S}$ is an adsorption site.

The direct and inverse rate constants are $k$ and $k-1$. If we define surface coverage, $\theta$, as the fraction of the adsorption sites occupied, in the equilibrium we have

$$
K=\frac{k}{k_{-1}}=\frac{\theta}{(1-\theta) P} \quad \text { or } \quad \theta=\frac{K P}{1+K P} .
$$

For very low pressures and for high pressures

$\theta$ is difficult to measure experimentally; usually, the adsorbate is a gas and the adsorbed quantity is given at standard temperature and pressure (STP) volume per gram of adsorbent. Therefore, if we call $v_{\text {mon }}$ the STP volume of adsorbate required to form a monolayer on the adsorbent (per gram of 
adsorbent too), and we obtain an expression for a straight line:

$$
\frac{1}{v_{\text {mon }}}=\frac{1}{K v_{\text {mon }}} \frac{1}{P}+\frac{1}{v_{\text {mon }}} .
$$

In the liquid, Langmuir adsorption model is based on the assumption that maximum adsorption corresponds to a saturated monolayer of solute molecules on the adsorption surface. The Langmuir equation can be described by the linearized form:

$$
C_{\mathrm{e}} / Q_{\mathrm{e}}=1 /\left(Q_{\mathrm{o}} \times K L\right)+C_{\mathrm{e}} / Q_{\mathrm{o}},
$$

where $Q_{\mathrm{o}}(\mathrm{mg} / \mathrm{g})$ is the maximum amount of metal ion per unit mass of activated tea waste for a complete monolayer on the surface and $K L$ is the equilibrium adsorption constant which is related to the affinity of the binding sites. $Q_{\mathrm{o}}$ represents a practical limiting adsorption capacity when the surface is fully covered with metal ions and allows the comparison of adsorption performance, particularly in the cases where the sorbent did not reach its full saturation in experiments [6].

\subsubsection{Freundlich adsorption isotherm}

Freundlich adsorption isotherm encompasses the heterogeneity of the surface and the exponential distribution of the sites and their energies. This equation can also be used to explain the variation of adsorption with concentration over a limited range at constant temperature. The Freundlich adsorption isotherm can be expressed as

$$
q_{e}=K_{F} \times C_{e}^{1 / n}
$$

where $K_{F}$ and $n$ are constants and $n$ is $>1$.

The adsorption data of lead are also analyzed by Freundlich model. The logarithmic form of the Freundlich model is given by the following equation:

$$
\ln Q_{e}=\ln K_{F}+(1 / n) \ln C_{e},
$$

where $Q_{e}$ is the amount adsorbed $(\mathrm{mg} / \mathrm{g}), C_{e}$ is the equilibrium concentration of the adsorbate $(\mathrm{mg} / \mathrm{l})$ and $K_{F}$ and $n$ are Freundlich constants related to adsorption capacity and adsorption intensity, respectively [7].

\subsubsection{Frumkin isotherm}

Frumkin isotherm is an extension of Langmuir isotherm. It states that adsorbed molecules do interact and affect further adsorption by either repulsion or attraction of molecules.

$$
\delta G_{\text {Frumkin }}=\delta G_{\text {Langmuir }}-2 g \Gamma_{i} .
$$

\subsubsection{BET isotherm}

Often molecules do form multilayer, that is, some are adsorbed on already adsorbed molecules and the Langmuir isotherm is not valid. BET isotherm takes into account that possibility. The proposed mechanism is now

$$
\begin{gathered}
\mathrm{A}_{(\mathrm{g})}+\mathrm{S} \rightleftharpoons \mathrm{AS} \\
\mathrm{A}_{(\mathrm{g})}+\mathrm{AS} \rightleftharpoons \mathrm{A}_{2} \mathrm{~S} \\
\mathrm{~A}_{(\mathrm{g})}+\mathrm{A}_{2} \mathrm{~S} \rightleftharpoons \mathrm{A}_{3} \mathrm{~S} .
\end{gathered}
$$


The derivation of the formula is more complicated than Langmuir's and given as:

$$
\frac{x}{v(1-x)}=\frac{1}{v_{\mathrm{mon}} c}+\frac{x(c-1)}{v_{\mathrm{mon}} c} .
$$

where $x$ is the pressure divided into the vapor pressure for the adsorbate at that temperature, $v$ is the STP volume of adsorbed adsorbate, $v_{\text {mon }}$ is the STP volume of the amount of adsorbate required to form a monolayer and $c$ is the equilibrium constant $K$ we used in Langmuir isotherm multiplied by the vapor pressure of the adsorbate. The biggest step in BET isotherm is to consider that the successive equilibrium for all the layers except for the first are equal to the liquefaction of the adsorbate. Langmuir isotherm is usually better for chemisorption and BET isotherm works better for physisorption.

\subsection{Adsorption enthalpy}

Adsorption is an exothermic process because energy is liberated, therefore enthalpy is always negative. Adsorption constants are equilibrium constants, therefore they obey Van't Hoff's equation:

$$
\left(\frac{\partial \ln K}{\partial \frac{1}{T}}\right)_{\theta}=-\frac{\Delta H}{R} .
$$

As can be seen in the formula, the variation of $K$ must be esoteric, that is, at constant coverage. If we start from BET isotherm and assume that the entropy change is the same for liquefaction and adsorption we obtain $\Delta H_{\text {ads }}=\Delta H_{\text {liq }}-R T \ln c$, that is to say, adsorption is more exothermic than liquefaction.

\section{ADSORBENTS USED}

Different adsorbents are widely used for removal of lead like granular activated carbon, bagasse fly ash, palm shell activated carbon, carbon from coconut shell, carbon aerogel, sea nodule, chemically modified activated carbon. Some adsorbents and their typical surface areas are listed below in the Table 3.

\section{EXPERIMENTAL FINIDINGS AVAILABLE IN LITERATURE}

\subsection{Adsorption by treated granular activated carbon}

The adsorption of $\mathrm{Pb}$ (II) onto activated carbon and treated activated carbon has been studied by batch as well as column studies and and it can be seen that the extent of lead removal is higher in the treated activated carbon. In the present study, mainly two types of adsorbents are explored: one is commercial activated carbon and other is alkali sulfide treated activated carbon. The idea following enriching the sulfur content of commercial activated carbon is that heavy metals have more affinity for sulfide than other anions as can also be seen from natural occurrence of most of the metals in their sulfide form. The chemical affinity of the lead towards the sulfur groups is higher. This is also consistent with the fact that molecules where donor atoms is $\mathrm{F}, \mathrm{O}$ or $\mathrm{N}$ are very hard, where as for the similar molecules where the donor atom is $\mathrm{Cl}, \mathrm{S}$ or $\mathrm{P}$ there is always a large drop in absolute hardness. As lead chemical show a high affinity towards sulfur, a tentative method of enhancing the adsorption capacity of activated carbon could be based on the introduction of surface sulfur in the 
Table 3: Characterization of adsorbents.

\begin{tabular}{lc}
\hline Adsorbents & Surface area $\left(\mathrm{m}^{2} / \mathrm{g}\right)$ \\
\hline Granular activated carbon & 1000 \\
Activated carbon from coconut shell & 265.96 \\
Bagasse fly ash & 450.0 \\
Palm shell activated carbon & 957.04 \\
Carbon aerogel & 700.0 \\
Saw dust based activated carbon & 192.0 \\
Red mud & 108.0 \\
Activated phosphate & 22.22 \\
Natural phosphate & 13.89 \\
Phosphogypsum & $11.0-13.0$ \\
Olive cake & 18.14 \\
Modified activated carbon & 900.0 \\
Saw dust based activated carbon & 192.0 \\
Lignin & 180 \\
\hline
\end{tabular}

material [8]. Moreover, the chemical treatment was essentially required to introduce suitable sulfur groups on its surface for the improvement in the adsorption affinity and efficiency of the activated carbon [9]. Coconut shell based granular activated carbon, produced by Active Carbon Limited (Hyderabad, India) is used as precursor in the study. The carbon is washed in distilled water to remove the fine impurities, oven dried at $110^{\circ} \mathrm{C}$ for $6 \mathrm{~h}$ and stored in plastic containers for further use and this adsorbent is termed as AC. To enrich the sulfur percentage $99.5 \mathrm{~g}$ of AC is immerged for $24 \mathrm{~h}$ in minimum quantity of distilled water containing $0.5 \mathrm{~g}$ of $\mathrm{Na}_{2} \mathrm{~S}$. The mixture is heated almost to dryness and dried in an oven for $4 \mathrm{~h}$ at $110^{\circ} \mathrm{C}$. The dried sample is washed with distilled water several times until it gives nil concentration of sulfide. The washed sample is again dried at $110^{\circ} \mathrm{C}$ for $4 \mathrm{~h}$ cooled in the desiccators and stored in the airtight container from aqueous solution for further use. Stock solution of $\mathrm{Pb}$ (II) is prepared ( $1000 \mathrm{mg} / \mathrm{l})$ by dissolving the required amount of, $\mathrm{Pb}\left(\mathrm{NO}_{3}\right)_{2}$ in acidified double distilled water. This stock solution is diluted with distilled water to obtain the desired concentration ranging from 5 to $70 \mathrm{mg} / 1$ [10].

\section{2 $\mathrm{Pb}$ (II) removal onto activated carbon prepared from coconut shell}

Removal of $\mathrm{Pb}$ (II) from aqueous solution by adsorption onto coconut shell carbon (CSC) is investigated. Adsorption of $\mathrm{Pb}(\mathrm{II})$ is strongly affected by $\mathrm{pH}$. CSC exhibits highest lead adsorption capacity at $\mathrm{pH}$ 4.5. Isotherms for adsorption of lead on CSC have been developed and it can be seen that the equilibrium data fit well to the Langmuir, Freundlich and Tempkin isotherm models. There are various adsorbents, but still CSC can be prepared easily and it is very cheap [11].

Coconut shell is collected from oil industries. After collection, it is crushed, washed with demonized water and dried. There are many factors that affect the lead uptake. The uptake of lead ions increases with increasing agitation time. Particle size also plays important role. The percent removal of lead increases from $42 \%$ to $99 \%$ as the particle size decreases from 850 to $75 \mu \mathrm{m}$ for an initial concentration of $20 \mathrm{mg} / \mathrm{l} \mathrm{Pb}$ (II) solution. The extent of adsorption process increases with increasing specific surface 
area. The specific surface available for adsorption will be grater for smaller particles and hence present removal of metal increases as particle size decreases; for larger particles the diffusional resistance to mass transport is higher and most of the internla surface of the particle may not be utilized for adsorption. Consequently, the amount of $\mathrm{Pb}$ (II) adsorbed is small. Reed et al. [12] also used granular-activated carbon columns in removing lead and cadmium ions from aqueus waste steams.

\subsection{Removal of lead from aqueous solutions by activated phosphate}

Nriagu $[13,14]$ suggested the application of phosphate as an in situ method to control hazardous quantities of lead. The potential of using activated phosphate as a new adsorbent for the removal of $\mathrm{Pb}$ (II) from aqueous solution has been investigated. The kinetics of lead adsorption and adsorption process are compared for the natural phosphate and activated phosphate [15].

The results indicate the equilibrium is established in about $1 \mathrm{~h}$ for NP and $3 \mathrm{~h}$ for AP. The effect of the $\mathrm{pH}$ is examined in the range of 2-6. The maximum removal obtained in between $\mathrm{pH} 2$ and 3 for natural phosphate and 3 or 4 for activated phosphate. The maximum adsorption capacities at $25^{\circ} \mathrm{C}$ are 155.04 and $115.34 \mathrm{mg} / \mathrm{g}$ for AP and NP, respectively. The effect of temperature has been carried out at 25,35 and $45^{\circ} \mathrm{C}$. The data obtained from adsorption isotherms of lead at different temperatures fit to linear form of Langmuir adsorption equation. The geothermal behavior of lead indicates that phosphate, which is present in sufficient amounts, reduces the lead solubility. Thus phosphate minerals have the potential to immobilize lead in contaminated soils. Several insoluble lead orthophosphate minerals may form after $\mathrm{P}$ reaction with lead contaminated soils depending on the reaction conditions, such as $\mathrm{pH}$ and presence of other cations and anions. Both phosphate rocks and hydroxyapatite have been used as the primary P sources in these studies and both minerals effectively reduce lead solubility. Mainly calcinated phosphate is used as a acid or basic heterogeneous catalyst for several reactions.

After collection, the phosphate rock is washed in water and only the fraction between 100 and $400 \mu \mathrm{m}$ which contain the phosphate phases is used. It is then dried in oven for overnight at $105^{\circ} \mathrm{C}$ and then activated with nitric acid. It can be seen from adsorption study that AP is an effective adsorbent for removal of lead from industrial effluent rather than commercial species.

\subsection{Removal of lead from wastewater using bagasse fly - a sugar industry waste}

An inexpensive and effective adsorbent has been developed from bagasse fly ash, obtained from the sugar industry, for the dynamic uptake of lead. Lead can be adsorbed by the prescribed adsorbent upto $96-98 \%$. The adsorption is found to be exothermic in nature [2]. The developed adsorbent for the removal of lead ions is very useful, economical, rapid and reproductive. So, a low cost adsorbent using bagasse fly ash is used for the removal and recovery of lead ion. Bagasse fly ash, a waste material of sugar industry, is collected and then the material is treated with hydrogen peroxidides (100 volumes) at $60^{\circ} \mathrm{C}$ for $24 \mathrm{~h}$ to remove the adhering organic matter. The resulting material is then washed with deionized water, dried at $100^{\circ} \mathrm{C}$, powdered, ground and sieved to the desired particle size before use. The material is then stored in a vacuum desiccators for further use. It can be seen that the developed bagasse fly ash is found to be stable in water, dilute acids and basses. The composition of the adsorbent is $\mathrm{SiO}_{2} 60.5 \%, \mathrm{Al}_{2} \mathrm{O}_{3} 15.4 \%, \mathrm{CaO} 3 \%, \mathrm{Fe}_{2} \mathrm{O}_{3} 4.9 \%$ and $\mathrm{MgO} 0.81 \%$.

The loss on ignition is found to be $18.01 \%$ by weight. The density and porosity are found to be $1.01 \mathrm{~g} / \mathrm{cc}$ and 0.36 fractions, respectively. The various compounds are present in the adsorbent like mullite, haematite, kaolinite, $\alpha$-quartz and $\gamma$-alumina. Which are detected by XRD. The surface area is found to be $450 \mathrm{~m}^{2} / \mathrm{g}$, the lead concentration is kept at 5-7 ppm. During adsorption, the $\mathrm{pH}$ is also 
maintained in the range of $2-9$, but the maximum uptake takes place at $\mathrm{pH} 6$. The adsorbent dose can be varied within 2-16 g/l and the adsorption runs are carried out at different temperatures like 30, 40 and $50^{\circ} \mathrm{C}$. Various isotherms are involved like Langmuir and Freundlich adsorption isotherm. The removal of lead by bagasse fly ash takes place by particle diffusion mechanism. Laumakis et al. [16] also studied fly ash subgrades for removal of lead ions from wastewater.

\subsection{Removal of lead from aqueous solutions on palm shell activated carbon}

The performance of a commercially available palm shell carbon to remove lead ion from aqueous solutions by adsorption is studied $[17,18]$. The adsorption is carried out at $\mathrm{pH} 3$ and 5 . Palm shell activated carbon shows high adsorption capacity for lead ions, especially at $\mathrm{pH} 5$ with an ultimate uptake of $95.2 \mathrm{mg} / \mathrm{g}$. This high uptake shows the palm shell activated carbon as amongst the best adsorbents for lead ions. The diffuse layer surface complexation model is applied to predict the adsorption. The palm oil industries generate huge amounts of palm shell and some of this solid waste is usually used as fuel to produce process steam and for electricity in palm oil mills. However, a large portion of it is either burnt in open air or dumped in areas adjacent tot the mills, which creates high environmental and disposal problems. In recent years, the interest to palm shell has increased mainly due to the fact that the material has been shown to be an excellent source of high quality and low cost activated carbon. So, here the adsorption capacity of palm shell activated carbon to remove lead ions from stimulated wastewaters is studied. Langmuir adsorption isotherm is used to estimate the maximal capacity of the adsorbent to remove the lead ion. So it can be said that this adsorbent can be successfully applied for wastewater treatment to remove heavy metals. Addition of acid to the solution of lead improved total metal uptake especially at $\mathrm{pH} 5$.

4.6 Natural zeolite and conversion of oil shell ash into zeolite for removal of lead ion from wastewater

A by-product, fly ash from oil shell processing is converted into zeolite alkali hydrothermal activation using sodium hydroxide $[19,20]$. The activation is performed at different activation temperatures using $8 \mathrm{M} \mathrm{Na}_{2} \mathrm{~S}$. Zeolite performed in a closed reactor at $160^{\circ} \mathrm{C}$ for $24 \mathrm{~h}$. Powder patterns of X-ray diffraction analysis has shown that zeolite of type Na-PI is successfully synthesized at $29.5,32.2$ and $34.4^{\circ} \mathrm{C}$. The product is used as an ion exchanger for the treatment of wastewater for the removal of heavy metal ions and lead is the target metal ion. The adsorption capacity is estimated to be $70.58 \mathrm{mg} / \mathrm{g}$ of zeolite, when the initial concentration of lead ion is $100 \mathrm{mg} / \mathrm{l}$. The results are correlated using Redlich-Peterson and Sips models. A by-product of oil shell processing is ash, which is considered a serious environmental problem. So an alternative manner is the conversion of this ash into high-grade zeolite product, which is considered an environmental friendly product. To study the metal uptake by the surface of the produced zeolite, several dynamic adsorption equilibrium models are entitled in the order to fit experimental findings. Accordingly Redlich, Peterson and Sips models are considered. Natural zeolite in the form of clinoptilolite has been investigated for lead removal in battery and nuclear wastewater, respectively [21,22]. Chabazite as a natural zeolite exchanger for removal of lead ions from water was investigated by Pansimi and Collella [23].

\subsection{Removal of lead ions from industrial wastewater by different types of natural materials}

The adsorption capacity of different natural materials like bone powder, activated carbon, Nile rose plant powder and commercial carbon has been compared [3]. The V/m ratio has been chosen to 
$500 \mathrm{ml} / \mathrm{g}$. The adsorption process is affected by various parameters such as contact time, $\mathrm{pH}$ and concentration of lead solution. The uptake per cent of lead can be increased by increasing the $\mathrm{pH}$ value. The sequence of lead uptake percent at constant $\mathrm{pH}$ from certain concentration of $\mathrm{Pb}\left(\mathrm{NO}_{3}\right)_{2}$ solution by the different natural materials is in the order bone powder $>$ active carbon $>$ plant powder $>$ commercial carbon. The uptake percent of lead can also be increased by decreasing the concentration of lead at constant $\mathrm{pH}$. The different adsorption capacities are $100 \%$ by bone powder, $90 \%$ by active carbon, $80 \%$ by plant powder and $50 \%$ by commercial carbon.

Some other natural materials like biomass and bacterial cells have been tested by various researchers for the removal of lead ions from wastewater. Vecchio et al. [24] studied the removal of $\mathrm{Cu}, \mathrm{Pb}$ and Cd ions by biosorption on bacterial cells. Niu et al. [25] studied the adsorption of lead ions on nonliving penicillium chrysogenum biomass.

\subsection{Removal of lead from contaminated water bodies using sea nodule as an adsorbent}

Adsorption of water soluble lead on polymetallic sea nodule has been investigated [26]. Complete decontamination of lead is possible by appropriate sea nodule dosing. Both Freundlich and Langmuir isotherms may reasonably explain the adsorption mechanism. Chemically bound moisture plays a very crucial role in lead adsorption. Lead adsorption capacity of sea nodule has been estimated at $440 \mathrm{mg} / \mathrm{g}$ of sea nodule. Polymetallic sea nodule is an exotic naturally occurring material found in the large stretches of Pacific, Atlantic and Indian Ocean. It is a good adsorbent for cations and anions, so a study of removal of lead by sea nodule is reported here. Various adsorption parameters like adsorption dose, particle size and shaking time are optimized by maximum adsorption by the method of continuous variation by batch adsorption experiments. Various kinds of isotherms are involved on this like Freundlich and Langmuir isotherm.

\subsection{Removal of lead from aqueous solution by red mud - an aluminium industry waste}

Red mud, an aluminum industry waste, has been converted into an inexpensive and efficient adsorbent and used in the removal of lead from aqueous solutions [27]. The material shows good adsorption capacity and follows Freundlich and Langmuir models. Thermodynamic parameters indicate the feasibility of the process. Red mud is a waste material formed through the bayer process of alumina production in the aluminum industries [28]. The surface area is calculated as $108 \mathrm{~m}^{2} / \mathrm{g}$. The toxicity and colloidal nature of the red mud particles as well as the relatively the large quantity generated, create a serious pollution hazards and needs a search for an improved disposal techniques. The equilibriums attain between 8 and $10 \mathrm{~h}$. Shaking time in between 8 and $24 \mathrm{~h}$ gives particularly the same uptake. The $\mathrm{pH}$ range has been chosen as 1.0-6.0. But the maximum uptake takes place at $\mathrm{pH} 4$. The $\mathrm{pH}$ adjustment has been made by dilute base and dilute acid. The effect of temperature is studied at 30,40 and $50^{\circ} \mathrm{C}$. Furthermore, it is observed that the adsorption decreases with an increase in temperature indicating that the process is endothermic in nature. Adsorption study has been performed by various particle sizes, i.e. 50-100, 150-200 and 200-250 BSS mesh and it is found that as particle size decreases, the extent of adsorption increases this may be because of enhanced surface area available for adsorption.

\subsection{Removal of $\mathrm{Pb}$ (II) from aqueous solution by adsorption on carbon aerogel}

Recently, a new form of activated carbon has appeared: carbon aerogel (CA). Its use for the adsorptive removal of inorganic compounds has not been studied [29]. The influence of different parameters, adsorbent concentration $(0.02-0.1 \mathrm{~g}), \mathrm{pH}(2-7)$ and temperature $\left(20-70^{\circ} \mathrm{C}\right)$, on the percentage 
removal of $\mathrm{Pb}(\mathrm{II})$ is also examined, using a response surface methodological approach. The optimum condition for maximum removal is found out at adsorbent concentration $(0.1 \mathrm{~g}), \mathrm{pH}$ range (4-7), and temperature $\left(20-70^{\circ} \mathrm{C}\right)$.

Carbon aerogel is derived from the sol gel polymerization of the metal alkoxides or certain multifunctional organic monomers followed by supercritical drying with $\mathrm{CO}_{2}$. Aerogels are microcellular foam materials, which are composed of interconnected particles with microscopic interstitial pores, they are quite porous, have an area-to-mass ratio of $700 \mathrm{~m}^{2} / \mathrm{g}$ and have a controllable pore size distribution $(\leq 50 \mathrm{~nm})$. The most of the metal ions are removed within the first $30 \mathrm{~min}$. of the adsorption run the removal of $\mathrm{Pb}$ (II) increases with increasing adsorbent mass and it shows a maximum removal of $96.78 \%$ at a carbon mass $0.08-0.1 \mathrm{~g}$. This is due to the availability of the more surface area with more functional groups at a higher mass of adsorbent. The adsorption capacity $Q_{0}$, from Langmuir model is found as $35 \mathrm{mg} / \mathrm{g}$ of $\mathrm{Pb}(\mathrm{II})$.

\subsection{Removal of $\mathrm{Pb}(\mathrm{II})$ from aqueous solutions by olive cake}

The removal of heavy metals from wastewater using olive cake as an adsorbent is investigated. Maximum desorption of $\mathrm{Pb}(\mathrm{II})$ ion is found to be $95.92 \%$ by $0.5 \mathrm{M} \mathrm{HNO}_{3}$ [30].

Olive cake is a waste of olive factory and usually used as heating, fertilizer and feeding material. Its structure contains organic compounds like lignocellulosic material, polyphenols and also amino acid, protein, oil and tannin. The olive cake, which is collected from olive industry, is washed with distilled water and dried with room temperature. The material is ground with a grinding mill to obtain 212-132 $\mu \mathrm{m}$ particle size. The highest value of adsorbate $\mathrm{Pb}$ (III) on olive cake is reached at $60 \mathrm{~min}$, i.e. $97.34 \%$ at $\mathrm{pH} 4.89$. The $\mathrm{Pb}$ (II) removal percentage value reached up to 82.5 with 4.135 estimated error at $\mathrm{pH}$. The effect of temperature varies from 20 to $35^{\circ} \mathrm{C}$ with an increment of $5^{\circ} \mathrm{C}$. Olive cake has an aromatic containing a large number of hydrogen of labile methoxy groups. These functional groups are known to serve as excellent bonding sites as well as cations exchange sites for heavy metals. The maximum capacity is $18.14 \mathrm{mg} / \mathrm{g}$ of the olive cake for lead.

\subsection{Removal of $\mathrm{Pb}$ (II) from aqueous solution by using bentonite}

The ability of bentonite clay to remove lead from aqueous solutions is studied at different optimized conditions of concentrations, amount of adsorbent, temperature, concentration of electrolyte and $\mathrm{pH}$ [31]. Maximum adsorption of $\mathrm{Pb}(\mathrm{II})$, i.e. $>98 \%$ has been achieved in aqueous solutions [32]. Bentonite is highly valued for their adsorptive properties, which from their high surface area and their tendency to absorb water in the interlayer sites. The time-dependent behavior of lead adsorption is measured by varying the equilibrium time between adsorbate and adsorbent in the range of 5-60 min. There is also the effect of amount of bentonite. The percentage adsorption and distribution coefficient increase with increasing the amount of adsorbent up to $0.5 \mathrm{~g}$. Percentage adsorption remains constant above $0.5 \mathrm{~g}$ but $K_{\mathrm{D}}$ decreases drastically. The $\mathrm{pH}$ has also a significant effect of the adsorption the adsorption of lead increases 30-94.5\% with an increase in $\mathrm{pH}$ of the solution from 1.4 to 3.4 and then decreases to $40 \%$ at $\mathrm{pH}$ 5. The equilibrium data for $\mathrm{Pb}(\mathrm{II})$ over the concentration range from 100 to $400 \mu \mathrm{g} / \mathrm{ml}$ at 25, 30, 40 and $50^{\circ} \mathrm{C}$ have been correlated with the Langmuir isotherm and Freundlich isotherm, respectively.

\subsection{Lead adsorption from water and wastewater by polymerized banana stem in a batch reactor}

The aim of this research work is a kinetic and equilibrium study of the sorption of $\mathrm{Pb}(\mathrm{II})$ ion from water and wastewater by formaldehyde polymerized banana stem containing sulfonic acid groups. 
The adsorbent has been characterized using surface area analyzer, infrared spectroscopy and scanning electron microscopy measurements. The surface charge and the acid groups of the adsorbent are determined using potentiometric and acid base titrations, respectively. Batch experiments are performed under kinetic and equilibrium conditions [33]. The optimum $\mathrm{pH}$ range for the maximum removal of lead is 5-9. The maximum adsorption $98.5 \%$ and $89.9 \%$ takes place for an initial concentration of 10 and $25 \mathrm{mg} / \mathrm{l}$, respectively, at $\mathrm{pH}$ 6.0. The sorption process occurs in two stages: external mass transport occurs in early stage and intraparticular diffusion occurs in long-term stage. The diffusion coefficients, energies of activation and entropies of activation for both processes are calculated to determine theoretical behavior of the sorption process. In the external mass transfer process, the diffusion coefficient increases with increasing initial concentration while in the intraparticular diffusion process, the diffusion coefficient decreases with increasing initial concentration. The temperature dependence indicates the endothermic nature of the adsorption process. The adsorption data fit very well to the Freundlich adsorption isotherm in the studied concentration range of $\mathrm{Pb}(\mathrm{II})$ adsorption. Quantitative removal of $10.0 \mathrm{mg} / \mathrm{l} \mathrm{Pb}$ (II) in $50 \mathrm{ml}$ of battery manufacturing wastewater by $125 \mathrm{mg}$ of the adsorbent is observed at $\mathrm{pH}$ 6.0. The adsorbent can be repeatedly used without noticeable loss of capacity.

\subsection{Lead removal from wastewater by Phosphogypsum}

Phosphogypsum is a byproduct of the phosphate fertilizer industry that is produced in large quantities worldwide by the dehydrate wet phosphoric acid process [34]. As there is no possibility to reuse the Phosphogypsum, it is generally stored in the vicinity of the plant until a suitable and economical method of disposal is developed. The surface area is $11-13 \mathrm{~m}^{2} / \mathrm{g}$. The RPM is maintained at $3000 \mathrm{rpm}$. The four parameters are studied for the following case such as Phosphogypsum dosage, contact time, $\mathrm{pH}$ and initial concentration. The effect of adsorbent has been in the range of $2.5-40 \mathrm{~g}$ on removal of lead and it can be seen that removal of lead increases with increasing Phosphogypsum dosages. This increase in the removal of lead with the Phosphogypsum dosage is due to the availability of more surface area of the Phosphogypsum for adsorption. As the Phosphogypsum dosage increased above $10 \mathrm{~g} / \mathrm{l}$, the percentage removal of lead does not change remarkably. The dosage of the Phosphogypsum is therefore selected to be $10 \mathrm{~g} / \mathrm{l}$. The effect of contact time is also studied and can be seen that the removal mechanism is carried out by means of a rapid reaction within first 30 min, where $86.5 \%$ of lead removal occurs and then the adsorption occurs slowly. The equilibrium is attained after shaking for $30 \mathrm{~min}$. Thus in each experiment, the shaking time is set to $45 \mathrm{~min}$. The $\mathrm{pH}$ range is maintained in the range of $1-6$. At higher $\mathrm{pH}$ values lead ions are precipitated because of the high concentration of $\mathrm{OH}$ ions in the adsorption medium.

\subsection{Removal of lead ion from industrial wastewater by using tea waste}

Removal of heavy metal lead from industrial wastewater effluent by using waste tea leaves has become very popular [35]. It is a very cheap adsorbent. Waste tea leaves have shown very good adsorption capacity. The waste tea leaves, which we get after tea making is usually washed with distilled water and then dried at $110^{\circ} \mathrm{C}$ temperature. It is then directly used as an adsorbent. It shows $90 \%$ removal capacity without any kind of activation. If the tea leaf has been activated with sodium sulfide to implement sulfur group on the surface, it shows $99 \%$ adsorption capacity for lead ion. So, it could be used as an efficient adsorbent for removal of lead ion from industrial effluent in the near future. 
4.16 Removal of $\mathrm{Pb}(\mathrm{II})$ ions from industrial wastewater by using sawdust

Results obtained based an experiments carried out on a batch reactor showed that the removal of lead and cadimium through their binding onto pinus sylvestris sawdust is possible [36]. Taty-Costodes et al. [37] studied the potential of pinus sylvestris sawdust, in a continuous flow removal of $\mathrm{Pb}$ (II) ions from synthetic and industrial aqueous effluents. The kinetic parameters obtained in a batch process were used to scale-up the process on a mini-column and to choose the breakthrough model. The column experimental data concerning the volumes treated were correlated using the bed depth service time model. These experimental data closely fitted the bed depth service time model at $10 \%$ of the breakthrough curve. The results from the bed depth service time model on the mini-column were then used to design a pilot plant adsorption unit. The performance of the pilot plant column accurately agreed with that obtained from the mini-column. The experiments carried out in a dynamic reactor allowed to bring out the influence of various parameters on the efficiency of the pinus sylvestris sawdust. In addition, the process was checked for the treatment of industrial aqueous effluents on a pilot plant scale and the results were in accordance with those obtained from synthetic effluents.

\subsection{Adsorption of lead ions in aqueous solutions onto lignin}

Lignin is known to adsorb many heavy metal ions [38]. Lignin has strong resistance to chemical reactions and a high surface area $\left(180 \mathrm{~m}^{2} / \mathrm{g}\right)$ [39]. Molecular weight of polymeric lignin changes from 2000 to $15,000 \mathrm{~g} / \mathrm{mol}$ [40]. The properties of lignin reveal that it has a potential to be used as possible adsorption material to remove heavy metals from wastewaters. Adsorption of toxic metal ions ( $\mathrm{Pb}(\mathrm{II})$ and $\mathrm{Cd}(\mathrm{II})$ ) on to modified lignin beech and poplar woods by alkali glycerol delignification are presented by Demirbas [41]. The material exhibits good adsorption capacity and the adsorption data follow the Langmuir model. The maximum adsorption capacities are 8.2-9.0 and $6.7-7.5 \mathrm{mg} / \mathrm{g}$ of the modified lignin for $\mathrm{Pb}$ (II) and $\mathrm{Cd}(\mathrm{II})$, respectively. The maximum adsorption percentage is 95.8 for $\mathrm{Pb}(\mathrm{II})$ for $4 \mathrm{~h}$ at $57^{\circ} \mathrm{C}$ and is 95.0 for $\mathrm{Cd}(\mathrm{II})$ for $10 \mathrm{~h}$ at $17^{\circ} \mathrm{C}$. The adsorption of both the metal ions increased with increasing temperature indicating endothermic nature of the adsorption process. The maximum adsorption percentages of $\mathrm{Pb}$ (II) and $\mathrm{Cd}$ (II) ions decrease with time till 48 and $42 \mathrm{~h}$ and then again increase slightly with time. The adsorption of both heavy metal ions increases with $\mathrm{pH}$. The adsorption of $\mathrm{Pb}$ (II) ions reached a maximum at a 5.0 value of $\mathrm{pH}$.

\subsection{Use of aquatic plants for removal of lead from wastewater}

Different aquatic plants have been found to have varying heavy metal ion removal rates from the surrounding water. Srivastava et al. [42] used the aquatic plants for the removal of lead and zinc ions from wastewater. The ability of Microspora (a micro alga) and Lemna minor (an aquatic plant) to remove soluble lead and nickel under various laboratory conditions was investigated [43]. Microspora was tested in a batch process with lead and nickel to examine the potential competition between metals for adsorption. The Microspora was exposed to $39.4 \mathrm{mg} / \mathrm{l}$ of lead over 10 days. Results show up to $97 \%$ of the lead was removed in the batch process and $95 \%$ in the semi-batch process. Initial concentrations below $50 \mathrm{mg} / \mathrm{l}$ (a dose that kills the algae) had no effect on the final concentration. The Lemna minor was exposed to lead and nickel using a full $3^{2}$ factorial experimental design (nine experiments, plus replications). Initial lead concentrations were $0.0,5.0$ and $10.0 \mathrm{mg} / \mathrm{l}$ and nickel concentrations were $0.0,2.5$ and $5.0 \mathrm{mg} / \mathrm{l}$ in the experiment. Overall, Lemna minor removed $76 \%$ of 


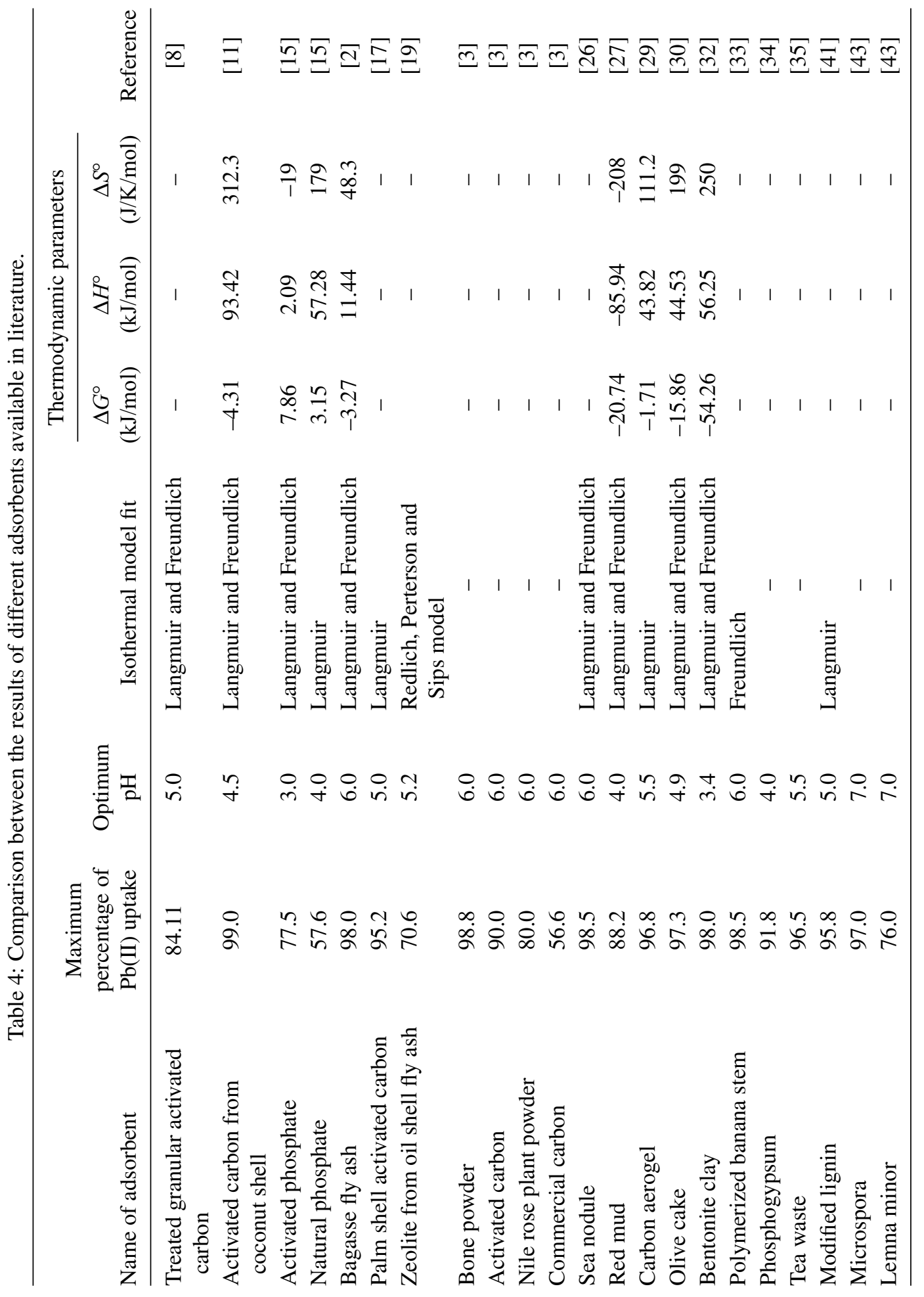


the lead and $82 \%$ of the nickel. No synergistic/ antagonistic effect was noted for the multiple metal experiments, in terms of metal removal.

\section{DISCUSSION}

The synthetic and industrial wastewater samples were treated by using the different natural materials to remove lead ions. Good results were obtained in various researchers where lead was efficiently removed by different natural materials. Inexpensive, effective, readily available materials can be used in place of commercially available conventional adsorbents for the removal of $\mathrm{Pb}$ (II) from solution. Comparisons of the adsorbents are difficult because of inconsistencies in data presentation. However, from the literature reviewed, the sorbents used by various workers were compared in terms of maximum percent removal efficiency of $\mathrm{Pb}(\mathrm{II})$. The comparison between the results of different adsorbents available in literature for $\mathrm{Pb}(\mathrm{II})$ uptake is given in Table 4. It was noticed that tea waste can be used as an efficient adsorbent for $\mathrm{Pb}$ (II) removal from industrial wastewater. Activation of tea waste may be needed to introduce suitable sulfur groups on its surface for the improvement of adsorption affinity towards the capture of $\mathrm{Pb}$ (II) ions from the solution. Although, improved adsorption capacity may compensate the cost of additional processing and activated tea waste may be a better option with a complete reusability, biodegradable and easy handling. Tea waste is simply the waste that results after the tea making process. To exploit growing opportunities at home and abroad, it can be used to remove harmful heavy metal, i.e., $\mathrm{Pb}(\mathrm{II})$, ions from the wastewater streams and thus can contribute to sustainable development.

\section{CONCLUSION}

The presence of different heavy metals in the aquatic environment has become a serious problem today. Lead is of particular interest because of its high toxicity. The removal for lead is very necessary. Various removal methods, which are available for the removal of lead from industrial wastewater and adsorption has far been chosen the most suitable and the cheapest method by different workers. The development of a suitable adsorbent is also very important. In this paper, a comparison study between different adsorbents has been made. There are various commercial adsorbents like activated carbon, carbon aerogel, bentonite etc., which have a good adsorption capacity. Comparative study between the commercial adsorbents and the adsorbents prepared from various natural materials has also been made. Some prepared adsorbents really have good adsorbent capacity in comparison with commercial adsorbents. A suitable adsorbent means not only the adsorbent should be less expensive but it also should be easily available or can be easily synthesized. From the thorough literature survey, it is seen that tea waste may be used as an effective adsorbent for removal of lead ion from industrial wastewater effluent. Without any activation it shows a good agreement in comparison with other adsorbents regarding the lead uptake from industrial wastewater. An efficient adsorbent could be developed from waste tea leaves, which would be attractive not only from economic point of view but also for minimum environmental impact.

\section{ACKNOWLEDGEMENT}

The Author gratefully acknowledges Banaras Hindu University for providing the necessary help for carrying out the present work.

\section{REFERENCES}

[1] Krishna Murti, C.R. \& Viswanathan, P., Toxic Metals in the Indian Environment, Tata McGraw-Hill: New Delhi, 1991.

[2] Gupta, V.K. \& Ali, I., Removal of lead and chromium from wastewater using bagasse fly ash - a sugar industry waste. Journal of Colloid and Interface Science, 271, pp. 321-328, 2004. 
[3] Halim, A.S.H., Shehata, A.M.A. \& Shahat, El.M.F., Removal of lead ions from industrial waste water by different types of natural materials. Water Research, 37, pp. 1678-1683, 2003.

[4] Yabe, S.J.M. \& Oliveira D.E., Heavy metals removal in industrial effluent by sequential adsorbent treatment. Advances in Environmental Research, 7, pp. 263-272, 2003.

[5] Maruyama, T., Hannah, S.A. \& Cohen, J.M., Metals removal by physical and chemical treatment processes. Journal of Water Pollution Control Federation, 47, pp. 440-445, 1975.

[6] Aksu, Z., Equilibrium and kinetic modeling of cadmium (II) biosorption by C. Vulgaris in a batch system: effect of temperature. Sep. Purif. Technol., 21, pp. 285-294, 2001.

[7] Weber, W.J., Physicochemical Processes for Water Quality Control. Wiley: New York, pp. 208, 1972.

[8] Goel, J., Kadirvelu, K., Rajagopal, C. \& Garg, V.K., Removal of lead(II) by adsorption using granulated activated carbon: batch and column studies. Journal of Hazardous Materials, 125B, pp. 211-220, 2005.

[9] Khalid, A.M. \& Mckay, G., Sorption of lead from aqueous solutions by chemically modified carbon adsorbents. Journal of Hazardous Materials, 138, pp. 604-613, 2006.

[10] Li, Z., Yang, Y., Tang, J. \& Pan, J., Spectrophotometric determination of trace lead in water after preconcentration using mercaptosephadex. Talant, 60, pp. 123-130, 2003.

[11] Sekar, M., Sakthi, V. \& Rengaraj, S., Kinetics and equilibrium adsorption study of lead (II) onto activated carbon prepared from coconut shell. Journal of Colloid and Interface Science, 279, pp. 307-313, 2004.

[12] Reed, B.E., Arunachalam, S. \& Thomas, B., Removal of lead and cadimium from aqueous streams using granular activated carbon columns. Environment Progress, 13, pp. 60-64, 1994.

[13] Nriagu, J.O., Lead orthophosphates: I. Solubility and hydrolysis of secondary lead orthophosphate. Inorganic Chemistry, II, pp. 2499-2503, 1972.

[14] Nriagu, J.O., Lead orthophosphates: II. Stability chloropyromorphite at $25^{\circ} \mathrm{C}$. Geochimica et Cosmochimica Acta, 37, pp. 1735-1743, 1973.

[15] Mouflih, M., Aklil, A. \& Sebti, S., Removal of lead from aqueous solutions by activated phosphate. Journal of Hazardous Materials, B119, pp. 183-188, 2005.

[16] Laumakis, M.T., Martin, P.J., Pamucku, S. \& Owens, K., Proceeding of the International conference on Hazard Waste Management. New York: ASCE, pp. 528-535, 1995.

[17] Issabayeva, G.Z., Aroua, K.M., Meriam, N. \& Sulaiman, N., Removal of lead from aqueous solutions on palm shell activated carbon. Bioresource Technology, 97, pp. 2350-2355, 2006.

[18] Krishnan Anoop, A. \& Anirudhan, T.S., Removal of lead(II) in the presence of organic ligand from aqueous solution using activated carbon. JEP, 22, pp. 52-59, 2002.

[19] Shawabkeh, R., Al-hrahsheh, A., Hami, M. \& Khlaifat, A., Conversion of oil shale ash into zeolite for cadmium and lead removal from wastewater. Fuel, 83, pp. 981-985, 2004.

[20] Turan, M., Mart, U., Yuksel, B. \& Celic, S.M., Lead removal in fixed-bed columns by zeolite and sepiolite. Chemosphere, 60, pp. 1487-1492, 2005.

[21] Petruzzelli, D., Pagano, M., Triavanti, G. \& Passino, R., Lead removal and recovery from battery waste waters by natural zeolite clinptilolite. Solvent Extr. Ion Exchange, 17, pp. 677-694, 1999.

[22] Faghihian, H., Ghannadi-Marageh, M. \& Kazemian, H., The use of clinptilolite of radioactive cegium and and strontium from nuclear waste water and lead, nickel, cadmium, barium from municipal waste water. Sep. Sci. Technol., 34, pp. 2275-2292, 1999.

[23] Pansini, M. \& Collella, C., Dynamic data on lead uptake from water by chabazite. Desalination, 78, pp. 287-295, 1990.

[24] Vecchio, A., Finoli, C., Di-Sinine, D. \& Andreoni, V., Heavy metal biosorption by bacterial cells. Fresenium Journal of Analytical Chemistry, 361, pp. 338-342, 1998. 
[25] Niu, H., Xu Xue, S., Wang, J.H. \& Volesky, B., Removal of lead from aqueous solutions by penicillium biomass. Biotechology and Bioengineering, 42, pp. 785-787, 1993.

[26] Bhattacharjee, S., Chakrabarty, S., Maity, S., Kar, S. Thakur, P. \& Bhattacharyya, G., Removal of lead from contaminated water bodies using sea nodule as an adsorbent. Water Research, 37, pp. 3954-3966, 2005.

[27] Gupta, K.V., Gupta, M. \& Sharma, S., Process development for the removal of lead and chromium from aqueous solutions using red mud - an aluminum industry waste. Water Research, 35(5), pp. 1125-1134, 2001.

[28] Naeem, A., Mustafa, S., Rehana, N., Dilara, B. \& Murtaza, M., Selective removal of Pb(II) by AlPo4. Environmental Technology, 24, pp. 779-765, 2003.

[29] Goel, J., Kadirvelu, K., Rajagopal, C. \& Garg, V.K., Removal of lead (II) from aqueous solution by adsorption on carbon aerogel using a response surface methodological approach. Industrial and Engineering Chemistry Research, 44, pp. 1987-1994, 2005.

[30] Doyurum, S. \& Ali, C., Pb(II) and Cd(II) removal from aqueous solutions by olive cake. Journal of Hazardous Materials, 138, pp. 22-28, 2006.

[31] Kaminari, N.M.S., Ponte, M.J.J.S., Ponte, H.A. \& Neto, A.C., Study of the operational parameters involved in designing a particle bed reactor for the removal of lead from industrial wastewater-central composite design methodology. Chemical Engineering Journal, 105, pp. 111-115, 2005.

[32] Naseem, R. \& Tahir, S.S., Removal of $\mathrm{Pb}(\mathrm{II})$ from aqueous/acidic solutions by using bentonite as an adsorbent. Water Research, 35, pp. 3982-3986, 2001.

[33] Noeline, B.F., Manohar, D.M. \& Anirudhan, T.S., Kinetic and equilibrium modeling of lead (II) sorption from water and wastewater by polymerized banana stem in a batch reactor. Sep. and Purif. Technol., 45, pp. 131-140, 2005.

[34] Balkaya, N. \& Cesur, H., Influence of operating parameters on lead removal from wastewater by phosphogypsum. Environmental Technology, 24, pp. 727-733, 2003.

[35] Mahvi, A.H., Naghipour, D., Vaezi, F. \& Nazmara, S., Teawaste as an adsorbent for heavy metal removal from industrial wastewaters. American Journal of Applied Science, 2(1), pp. 372-375, 2005.

[36] Taty-Costodes, V.C., These de I, Universite Pierre at Marrie Curie, Paris VI, pp. 1-301, 2003.

[37] Taty-Costodes, V.C., Fauduet, H., Porte, C. \& Ho, Y.S., Removal of lead(II) ions from synthetic and real effluents using immobilized pinus sylvestries sawdust: adsorption on a fixed-bed column. Journal of Hazardous Materials, B123, pp. 135-144, 2005.

[38] Pahlman, J.E. \& Khalafalla, S.E., Use of Lignichemicals and Humic Acids to Remove Heavy Metals from Process Waste Streams, Bureau of Mines, US Department of the Interior, RI 9200, 1988.

[39] Sjotrom, E., Wood chemistry fundamentals and applications, Academic press Inc.: New York, 1981.

[40] McDonald, G.R., The Pulping of Wood, I, 2nd edn, pp. 56-63, 1992.

[41] Demirbas, A., Adsorption of lead and cadamium ions in aqueous solutions into modified lignin from alkali glycerol delignieation. Journal of Hazardous Materials, B109, pp. 221-226, 2004.

[42] Srivastava, R.K., Gupta, S.K., Nigam, K.D.P. \& Vasudevan, P., Use of aquatic plants for the removal of heavy metals from waste waters. International Journal of Environmental Studies, 45, pp. 43-50, 1993.

[43] Axtell, N.R., Sternberg, S.P.K. \& Claussen, K., Lead and nickel removal using Microspora and Lemna minor. Bioresource Technology, 89, pp. 41-48, 2003. 